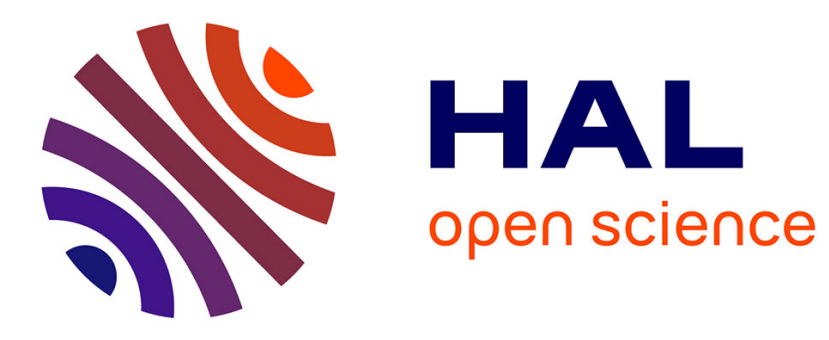

\title{
Imaginaire et images de la grotte dans la Grèce archaïque et classique
}

Gérard Siebert

\section{To cite this version:}

Gérard Siebert. Imaginaire et images de la grotte dans la Grèce archaïque et classique. KTÈMA Civilisations de l'Orient, de la Grèce et de Rome antiques, 1990, 15, p. 151-161. halshs-00001025

\section{HAL Id: halshs-00001025 https://shs.hal.science/halshs-00001025}

Submitted on 13 Jan 2004

HAL is a multi-disciplinary open access archive for the deposit and dissemination of scientific research documents, whether they are published or not. The documents may come from teaching and research institutions in France or abroad, or from public or private research centers.
L'archive ouverte pluridisciplinaire HAL, est destinée au dépôt et à la diffusion de documents scientifiques de niveau recherche, publiés ou non, émanant des établissements d'enseignement et de recherche français ou étrangers, des laboratoires publics ou privés. 
Ktema 15, 1990

\section{Imaginaire et images de la grotte dans la Grèce archaïque et classique}

Dans ses Recherches sur la grotte à Rome (*) H. Lavagne montre comment, à l'époque hellénistique, la transformation de l'antre naturel et sauvage en construction artificielle, son entrée dans la cité, constituent un événement dans l'histoire de la pensée et de l'art antiques. Accomplie architecturalement et plastiquement à Alexandrie $\left(^{1}\right)$, une rupture se produit avec un héritage immémorial, même si, a posteriori, on en devine les germes dans des modèles littéraires classiques: que l'on songe à la grotte de Philoctète, telle qu'elle se métamorphose à la fin de la pièce de Sophocle ou, antérieurement, à celle des Nymphes d'Ithaque et même, contre toute attente, à la caverne de Polyphème. Des contradictions semblent se résoudre qui, dans l'imaginaire grec et, plus intemporellement, dans l'esprit de tout homme, affectent l'appréhension de la grotte. H. Lavagne va droit à l'essentiel en citant à la première page de son livre le texte de Léonard de Vinci, disant devant la grotte sa peur et son désir :

«paura e desidero ; paura per la minacciante e scura spilonca, desidero per vedere se là entro fusse alcuna miracolosa cosa».

Dans un chapitre de La terre et les rêveries du repos, G. Bachelard donne en philosophe les clefs de ces songes $\left({ }^{2}\right)$. On trouvera dans Operosa antra les analyses et les références qui dispensent ici de tout propos général. On s'y reportera également avec profit à une enquête archéologique sur les antécédents grecs de la grotte romaine ( $\left.{ }^{3}\right)$.

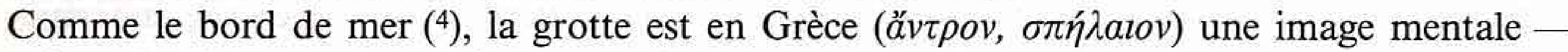
on vient de l'évoquer - , mais elle est d'abord et plus simplement un abri pour les bergers et les voyageurs, en cela semblable au havre que le rivage offre aux marins : pareillement lieux des confins stériles, mais imprégnables d'humanité et, malgré le mot de Sophocle (äorkoৎ

$\left({ }^{*}\right)$ Les principales revues sont citées selon les abréviations en usage dans le Bulletin de Correspondance Hellénique. Autres abréviations utilisées dans cet article : Grèce archaïque $=\mathrm{J}$. Charbonneaux, R. Martin, Fr. Villard, Grèce archaïque, Paris, Gallimard, L'Univers des formes, 1968 ; Operosa antra $=\mathrm{H}$. Lavagne, Operosa antra. Recherches sur la grotte à Rome, de Sylla à Hadrien, BEFAR 272, Paris, 1988; Metzger, Représentations = H. Metzger, Les représentations dans la céramique attique du IVe siècle, BEFAR, 172, Paris, 1951; Bérard, Anodoi $=\mathrm{Cl}$. Bérard, Anodoi. Essai sur l'imagerie des passages chthoniens, Bibliotheca Helvetica Romana, XIII, 1974 ; LIMC = Lexicon Iconographicum Mythologiae Classicae, Artemis Verlag, Zurich, 1981; MZ = E. Pfuhl, Malerei und Zeichnung der Griechen, 1923; CVA = Corpus Vasorum Antiquorum ; ABL = C. H. E. Haspels, Attic Black-figured Lekythoi, Paris, $1936 ; A B V=$ J. D. Beazley, Attic Black-figure Vase-painters, Oxford, 1956; ARV= J. D. Beazley, Attic Red-figure Vase-painters, Oxford, 1963 ; Para = J. D. Beazley, Paralipomena, Additions to Attic Black-figure Vase-painters and to Attic Red-figure Vase-painters, Oxford, 1971.

(1) Operosa antra, pp. 91-147.

(2) Paris, José Corti, 1948, pp. 185-208.

(3) G. SAuron, «De Buthrote à Sperlonga : à propos d'une étude récente sur le thème de la grotte dans les décors romains", Revue Archéologique $(=R A), 1991$, p. 4, rend hommage à l'auteur de l'enquête.

(4) On se reportera, dans ce même volume, à l'article de R. Buxton, pp. 163-172, et à son étude sur «Iphigénie au bord de la mern, Pallas, Revue d'Etudes Antiques, 38, 1992, pp. 209-215. 


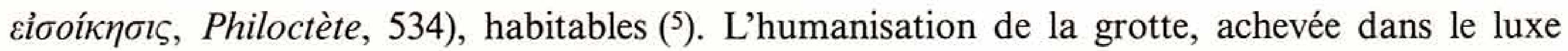
des operosa antra $\left(^{6}\right)$, commence très tôt dans l'iconographie grecque et très modestement. Géant "qui ne mange pas de pain" et couche dans le même fumier que ses bêtes, Polyphème n'en a pas moins équipé son antre de ce qu'il faut pour traiter le lait de ses troupeaux. Sur le cratère d'Aristonothos ( $\left.{ }^{7}\right)$, issu peut-être d'un atelier de Cumes dans le deuxième quart du $\mathrm{V}_{I I}{ }^{\mathrm{e}}$ siècle, l'ustensile qui se dresse derrière lui est généralement interprété, à la lumière du texte homérique (Odyssée, IX, 219), comme une de ces claies aménagées en hauteur pour faire sécher le fromage et le tenir hors de portée des animaux. Du reste, les alentours de la caverne sont aménagés en bergerie, avec une cour ( $\alpha \dot{v} \lambda \dot{\eta} \dot{v} \psi \eta \lambda \eta \dot{\eta})$ que dessinent des blocs de rocher et des troncs

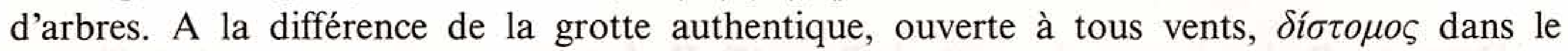
Philoctète, v. 16, et caractérisée par l'absence de porte, celle du Cyclope est munie d'une énorme

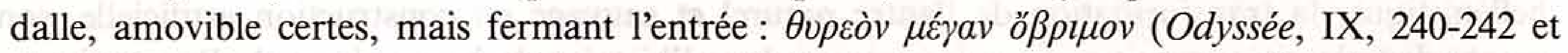
415-417). Paradoxalement, le Peintre de la Sirène, sur un stamnos de Malibu, joue de cette pierre comme d'un véritable signe de la grotte $\left({ }^{8}\right)$.

Il n'existe, dans la peinture de vases grecque, aucune image de la grotte des Nymphes située au-dessus du port d'Ithaque. Dans l'Odyssée, XIII, 103-112, on apprend qu'elle était sainte

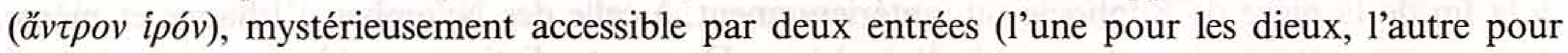
les hommes), aimable, visitée par les abeilles, industrieuse par ses métiers à tisser, donc munie elle aussi d'un équipement technique $\left(^{9}\right)$. Dans les représentations figurées, la présence de mobilier à l'intérieur des grottes ou à proximité immédiate obéit souvent à la logique du récit. Sur un skyphos corinthien du Musée du Louvre $\left({ }^{10}\right)$, la voûte de la grotte de Pholos surplombe la jarre indispensable à la mise en scène de l'épisode, près du foyer où brûle le feu pour rôtir les viandes servies à Héraclès, au lieu des viandes crues que consomme le centaure. Pour les mêmes raisons ne peut manquer, dans la grotte de Maia, le berceau de l'enfant Hermès, qu'il soit exhaussé comme sur les pieds d'un lit ou qu'il soit posé à même le sol et flairé par une vache ${ }^{(1)}$. Pourtant l'association de l'antre et du lit aura, dans toute la tradition grécoromaine, la même connotation : c'est la grotte des amants opposée au thalamos conjugal (12). La plus ancienne représentation figurée se trouvait probablement sur le registre supérieur (le

(5) Dans le premier volume de ses Modern painters, publié en 1843 en l'honneur de Turner, John Ruskin analyse ainsi ce sentiment : «Une subordination de la nature aux besoins de l'homme permet aux Grecs de prendre un certain plaisir au spectacle des rochers, mais seulement lorsqu'ils forment une grotte. Sous tout autre aspect, surtout s'ils sont vides et hérissés, ils en éprouvent de l'épouvante. S'ils sont au contraire polis et sculptés comme le flanc d'un navire, formant une grotte où ils puissent s'abriter, leur présence leur devient supportable» (éd. J. M. Dent, Londres, 1906, trad., p. 47).

(6) Les modèles en sont les constructions réalisées pour la pompè de Ptolémée Philadelphe et la thalamège de Ptolémée Philopator dont les descriptions sont transmises par Callixène de Rhodes à travers Athénée. Cf. Operosa antra, pp. 91-126.

(7) E. Simon, Die griechischen Vasen, Munich, 1981, p. 43 sq. et pl.19.

(8) Antike Kunst, 24, 1981, p. 66 et pl. 10, 3.

(9) Le paysage du port lui-même est représenté sur une pyxide du Musée d'Amiens, avec l'épisode du débarquement d'Ulysse endormi : I. Jucker, Mitteilungen des Deutschen Archäologischen Instituts, 4, 1951, pp. 135-138, pl. 7 sq. V. Bérard, Dans le sillage d'Ulysse. Album odysséen (rééd. Paris, 1973, par J. Bérard), pl. 25 sq. et index, situe la grotte au-dessus de la baie Dexia.

(10) Grèce archaïque, p. 45, fig. 47.

(11) Hydrie de Caeré au Musée du Louvre: J. M. Hemelrijk, Caeretan Hydriae, Leyde, 1980, pp. 10-12, n 3, fig. 4, pl. 29 sq.; G. Siebert, LIMC, V (1990), $\mathrm{n}^{\circ}$ 241. - Coupe du Peintre de Brygos, au Musée du Vatican : $A R V^{2}, 269,6 ; L I M C, \mathrm{~V}, \mathrm{n}^{\circ} 242$.

(12) Les exemples de Médée et de Jason, de Didon et d'Enée sont commentés dans Operosa antra, pp. 459-464. 
seul anépigraphe) du coffre de Kypsélos. Pausanias, V, 19, 7, identifie la couche d'Ulysse et de Circé, dont les servantes s'activent à préparer le repas ( $\left.{ }^{13}\right)$.

Aux grottes des amours, des naissances et des enfances divines, où Zeus, Hermès, Dionysos et bien d'autres ont grandi et ont aimé, s'opposent celles de la sauvagerie naturelle et, parfois, de la terreur religieuse, quand des traditions régionales conservent de vieilles légendes de l'Age du Bronze. En VII, 42, 1-13, Pausanias livre une version arcadienne du mythe d'Eleusis. Par colère contre Poséidon qui l'avait forcée et dans le chagrin d'avoir perdu Korè, Déméter se revêt de noir et se retire dans une caverne du Mont Elaion, non loin de Phigalie, déclenchant la famine dans tout le pays. Dans la caverne de Déméter Mélaina, on visitait un xoanon de la déesse, zoomorphe et tératomorphe, à tête chevaline et à crinière composée d'excroissances de serpents et d'autres bêtes sauvages $\left.{ }^{14}\right)$ : Déméter Erynis, dit encore Pausanias, image d'épouvante dans l'ombre. Et lorsque la destruction de l'effigie entraîne l'oubli du culte éclate une nouvelle disette, plus atroce que la première, à en croire les menaces de l'oracle de Delphes : si les gens de Phigalie ne rétablissent pas Déméter dans ses honneurs, ornant d'offrandes son ravin, ils reviendront à l'état de mangeurs de gibier et ils se mangeront les uns les autres. Mais la contre-épreuve se présente aussitôt. Dans le paysage du sanctuaire poliade d'Athènes, somptueusement construit de temples, le prestige des grottes du versant Nord paraît inséparable de celui des édifices : celles de Pan, d'Aglauros, d'Aphrodite et d'Eros, celle où Apollon s'était uni à Créüse et où Ion fut recueilli. Euripide, en 418 , brode la matière mythique en fonction

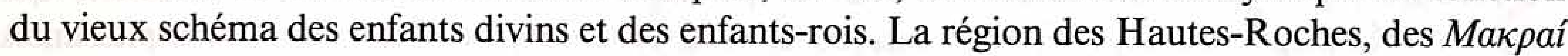
où le poète fait danser les Aglaurides avec l'enfant Erichthonios, réunit des cultes récents (celui de Pan) à ceux du plus lointain passé (15). Loin des solitudes de l'Arcadie, dans une culture qui est par excellence celle de la ville et de l'architecture, la fascination de la grotte n'a pas faibli. En ce sens - en ce sens seulement - son entrée dans la cité est bien antérieure à la construction des operosa antra.

Dès les premières représentations littéraires ou figurées la grotte est un paysage de pierre et de verdure, associant deux règnes de la nature $\left({ }^{16}\right)$. Ombragé de lauriers dans l'Odyssée, l'antre de Polyphème est fréquemment environné d'arbres, en avant du rocher creux, dans l'épisode de la fuite d'Ulysse et de ses compagnons, tel qu'il est mis en scène par la peinture de vases archaïque (Pl. I, 1) $\left.{ }^{\left({ }^{17}\right.}\right)$. Il en va de même pour les cavernes du lion de Némée et du serpent Python à Delphes $\left({ }^{18}\right)$. Sur le coffre de Kypsélos, Dionysos était couché dans une

(13) Le peintre corinthien avait bien représenté une grotte de Circé et Pausanias, pour l'évoquer, emploie le terme $\sigma \pi \eta ́ \lambda a \imath o v$. C'est en avant de l'antre que les servantes vaquent à leurs besognes. L'artiste amalgame deux visions qui semblent avoir eu cours à l'époque archaïque : celle de la grotte de la magicienne et, en raison du luxueux mobilier, celle du palais (du «manoir», comme traduit V. Bérard). Dans tout l'épisode - Odyssée, X, 348-360 et passim -, Homère utilise constamment des mots du vocabulaire architectural : $\tau \varepsilon \tau v \gamma \mu \varepsilon ́ v a ~ \delta \omega ́ \mu a \tau a, \pi \rho o ́ \theta v \rho o l, \theta v \rho a i ́$. Pour une transcription graphique du texte de Pausanias : N. D. Papachatzl, Pausanias Hellados Periegesis, Athènes, 1979, p. 297.

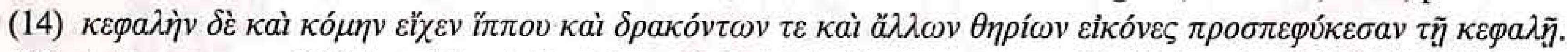

(15) J. Bousquet, «Delphes et les Aglaurides», Bulletin de Correspondance Hellénique (= BCH), 89, 1964, pp. 655-675.

(16) Même lorsque le sujet ne l'exige pas, des animaux sont fréquemment associés aux grottes, comme des signes supplémentaires du monde sauvage : lièvre bondissant parmi les buissons (hydrie de Caeré, supra, n. 11); lièvres et chevreuils à proximité des grottes dionysiaques et des grottes d'amour (par exemple sur le cratère lucanien de Toledo, H. 81.110 : CVA, USA 16, Toledo 2, pl. 92).

(17) Exemple caractéristique: le lécythe à figures noires 13788 au Musée de Copenhague ( $C V A$, Danemark 8 , Copenhague 8, pl. 329).

(18) Antre de Némée: lécythe du Peintre d’Athéna, proposé sur le marché de Bâle: Auktion 56, 1980, n 87, pl. 34. - Antre de Delphes: lécythe du Cabinet des Médailles, Paris, inv. 306 ; $A B V, 572,7$ («late Haemonian», proche du Peintre de Pholos); L. KAHiL, "Apollon et Python», Mélanges offerts à K. Michalowski, Varsovie, 1966, 
grotte précédée de vignes, de pommiers et de grenadiers (Pausanias, V, 19, 6-7) : c'est l'antre dionysiaque par excellence, absent du paysage des Bacchantes d'Euripide $\left({ }^{19}\right)$, mais décrit par

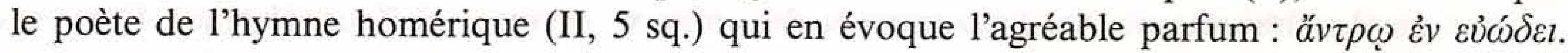
La composante végétale de la grotte ne cesse de gagner en importance à mesure que s'imposent, dans l'art du second classicisme grec, le goût paysagiste et la capacité de représenter graphiquement les arbres et les plantes. Au début du Ive siècle, un cratère attique de Berlin, montrant l'anodos d'une divinité chthonienne (Pl. III, 1 et 2), en constitue un exemple très caractéristique $\left({ }^{20}\right)$. Il est possible que la représentation purement minérale de la grotte de Philoctète par le Peintre de Dircé, à la même époque, témoigne d'une fidélité littérale à la tragédie de Sophocle, qui insiste sur l'aspect désertique du cap de Lemnos où séjourne le héros ${ }^{(21)}$. En effet, le même peintre (Pl. III, 3) parsème d'arbustes, selon le schéma ordinaire, la grotte où Antiope avait trouvé refuge et où ses fils se saisissent du roi Lykos $\left({ }^{22}\right)$. Contre toute vraisemblance, mais conformément au topos de l'imagerie, même la grotte marine devant laquelle fut exposée Andromède est garnie d'une abondance d'herbes et de fleurs (23).

Les éléments constitutifs de la grotte, le rocher et la végétation, sont liés au point que la seconde peut se substituer au premier. Sur un lécythe d'époque parthénonienne (Pl. I, 2), un arbre dessine comme une voûte protectrice au-dessus de Philoctète $\left({ }^{24}\right)$. On voit ici le passage de la grotte au berceau de verdure. Il arrive qu'Europe se trouve à l'abri de feuillages qui se recourbent au-dessus de sa tête et dont ne parlent ni Moschos ni aucun des poètes qui ont décrit la prairie du rapt $\left.{ }^{25}\right)$. Thématiquement, ce type de grottes-tonnelles, plus plaisantes que les antres rocheux, se confondent avec les grottes d'amour et, très souvent, avec les grottes dionysiaques, comme celle du sanctuaire bachique de Thasos, aménagée au $\mathrm{I}^{\text {er }}$ siècle de notre ère par le médecin Timocleidès : «un bel antre toujours vert, un berceau de pampres» (26).

pp. 481-490, pl. III. Un doublet existe au Musée de Bergen ( $C V A$, Norvège 1, pl. 33, 3-5; signalé par L. Kahil, p. 484, n. 4).

(19) Absence souvent relevée et expliquée par le fait que la nature tout entière est le sanctuaire de Dionysos (par ex. G. Roux, Delphes, son oracle et ses dieux, Paris, 1976, p. 161 sq.). L'étude classique est celle de P. BoyancÉ, «L'antre dans les mystères de Dionysos», Rendiconti della Pontificia Accademia Romana di Archeologia, 33, 1961, pp. 107-127.

(20) Berlin, inv. F 2646: $A R V^{2}, 1443,6$ (Peralta Reverse Group) ; MetzGer, Représentations, p. 75, $\mathrm{n}^{\circ}$ 17, pl. $13,1$.

(21) Cratère de Syracuse : CVA, Italie 17, Syracuse 1, pl. 8. Le tronc d'arbre sur le côté gauche de la scène sert simplement d'appui au héros en conversation avec Athéna : une sorte de «béquille», comme dans certaines sculptures de Praxitèle.

(22) Cratère de Berlin, vase éponyme du Peintre de Dircé : T. DoHrN, «Helden und Höhle», Römische Mitteilungen $(=R M), 84,1977$, p. 214, pl. 111 ; I. Th. KAKRIDIs, Helliniki mythologia, Athènes, 1966, p. 78, fig. 42. - On n'a pas souligné l'étrange construction du tableau, résultant de la compilation de deux épisodes : celui de la capture de Lykos et celui du supplice de Dircé. Le vêtement de la reine (hors de la grotte) touche, comme à travers la paroi, celui d'un fils d'Antiope représenté à l'intérieur. Sur ces problèmes de l'espace de la grotte, de la difficulté de figurer simultanément l'intérieur et l'extérieur, voir infra, pp. 155-159.

(23) Cratère de Berlin 3237. - $A R V^{2}, 1690$ (1336), cercle du Peintre de Pronomos; K. Schauenburg, LIMC, I, $1981, \mathrm{n}^{\circ} 8$ et pp. 625-628.

(24) Metropolitan Museum de New York, 56.171.58. - I. Th. KAKRIDIS, op. cit. (n. 22), V, p. 132, fig. 111.

(25) LIMC, IV, 1988, p. 32, $\mathrm{n}^{\circ} 4$; G. SiEBerT, «Images d'Europe», Actes du XXVe congrès international de l'Association des Professeurs de Langues Anciennes, 1992, pp. 42-49. Peut-on parler de "grotte» (sic, Operosa antra, p. 74) à propos du paysage platonicien de l'llissos (Phèdre, $233 \mathrm{~d}$ ) ? Il s'agit alors de la grotte de verdure, au sens où nous l'entendons ici, du "couvert du platane». Cf. aussi A. Motre, «Le pré sacré de Pan et des Nymphes», L'Antiquité Classique, 32, 1953, pp. 460-476.

(26) L'inscription de Thasos (Guide de Thasos, École française d'Athènes, 1968, p. 172) suggère que les grottes dionysiaques de la peinture de vases sont inspirées de grottes cultuelles réelles. Le cratère de Toledo (supra, n. 16) illustre assez bien l'épigramme votive de Timocleidès. - A propos de l'antre corycien à Delphes, P. AmANDRY, $B C H$, 


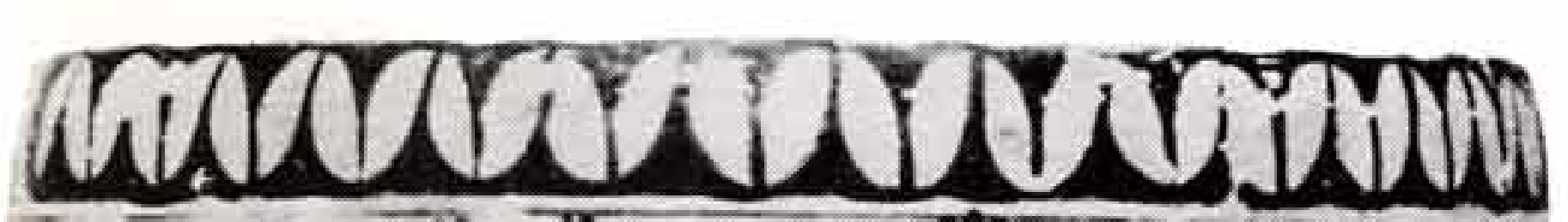

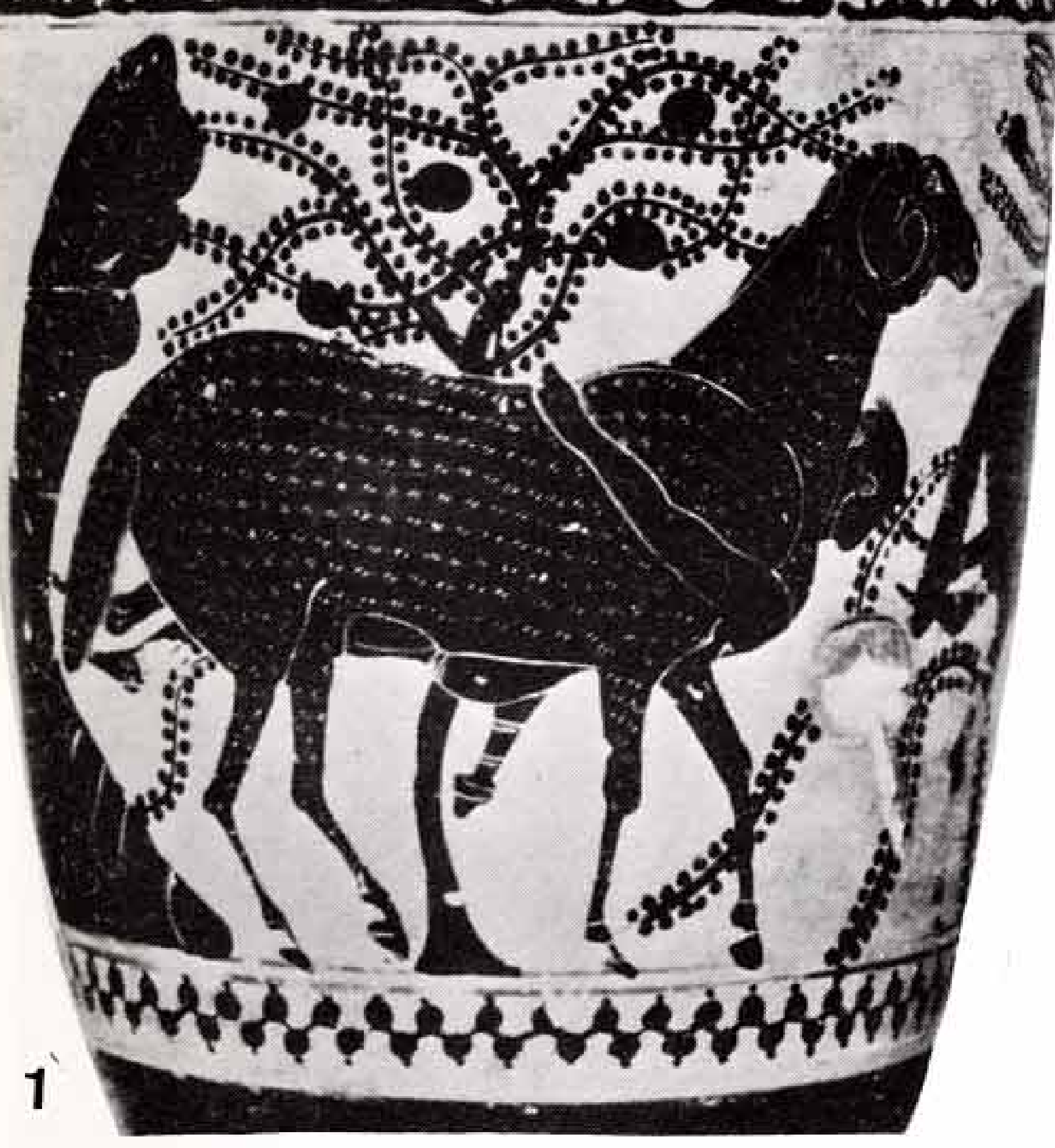

2

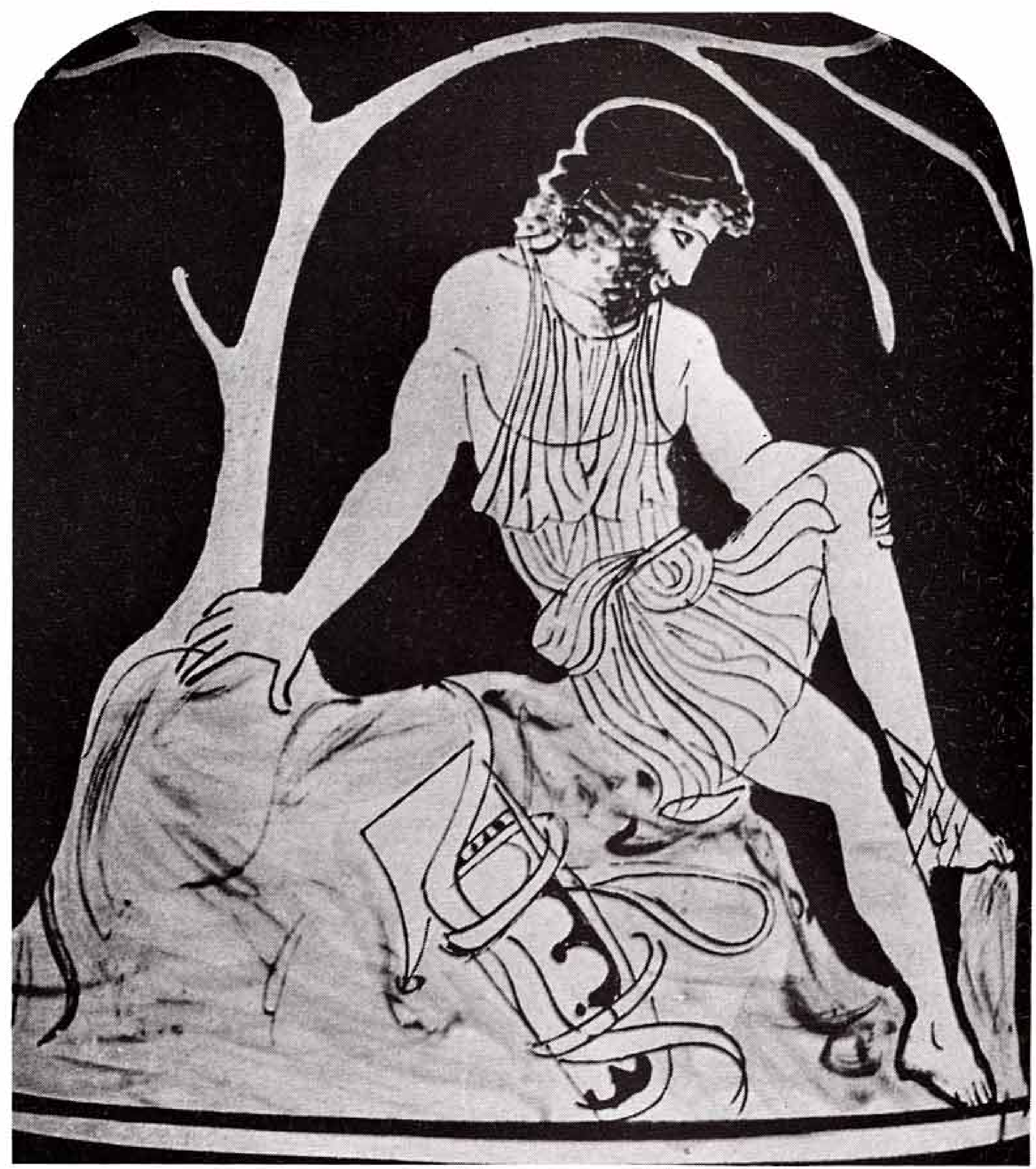

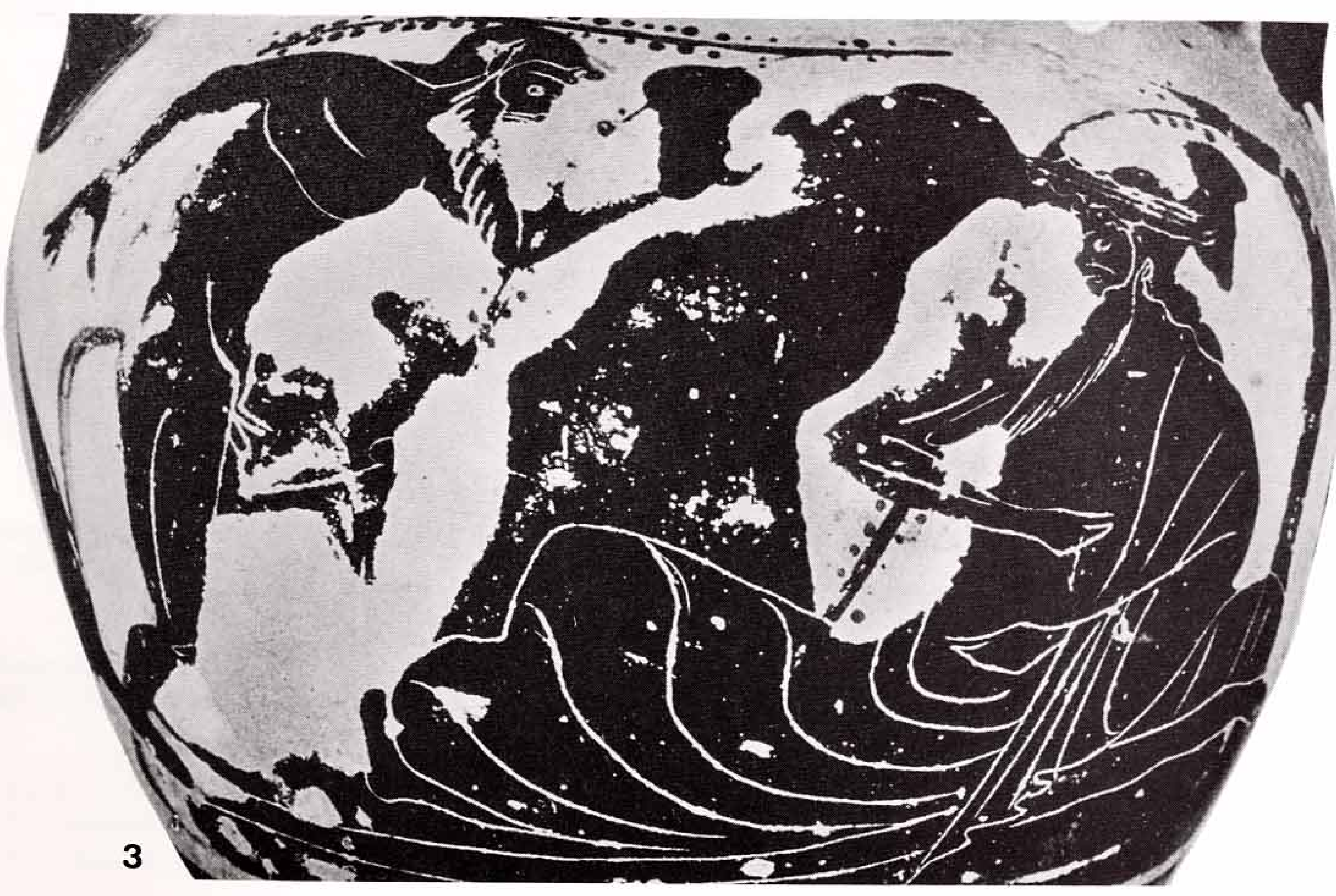

1. - Grotte de Polyphème. Paroi rocheuse et arbres. Vers 480 (CVA Danemark 8, pl. 329).

2. - Philoctète sous le couvert d'un arbre. Vers 430 (I. Th. KAKRIDIS, Helliniki Mythologia, V, p. 132, fig. 111).

3. - Grotte de Dionysos. Paroi rocheuse et berceau de pampres. Vers 500 ( CVA France 20, Laon 1, pl. 7, 3). 

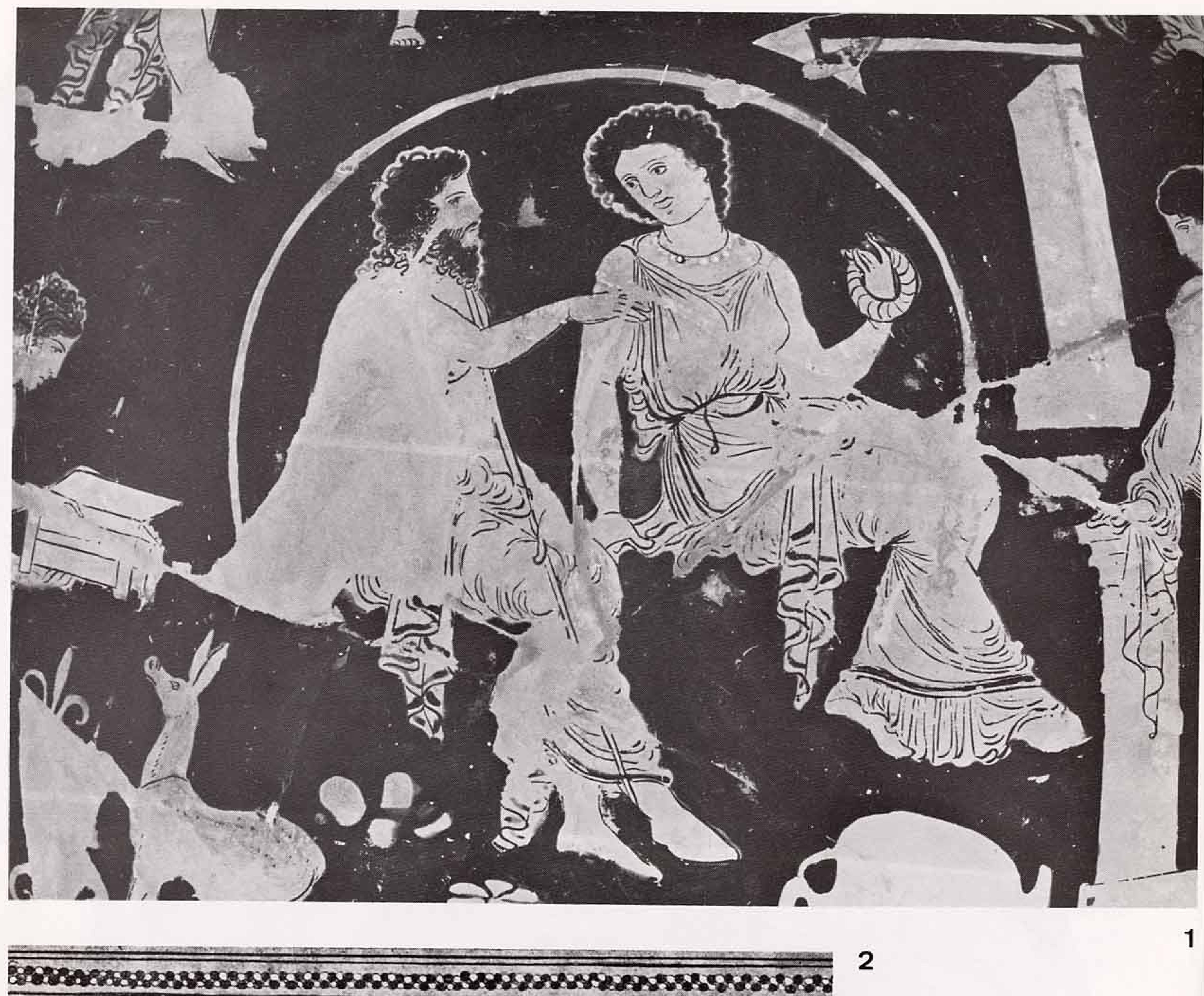
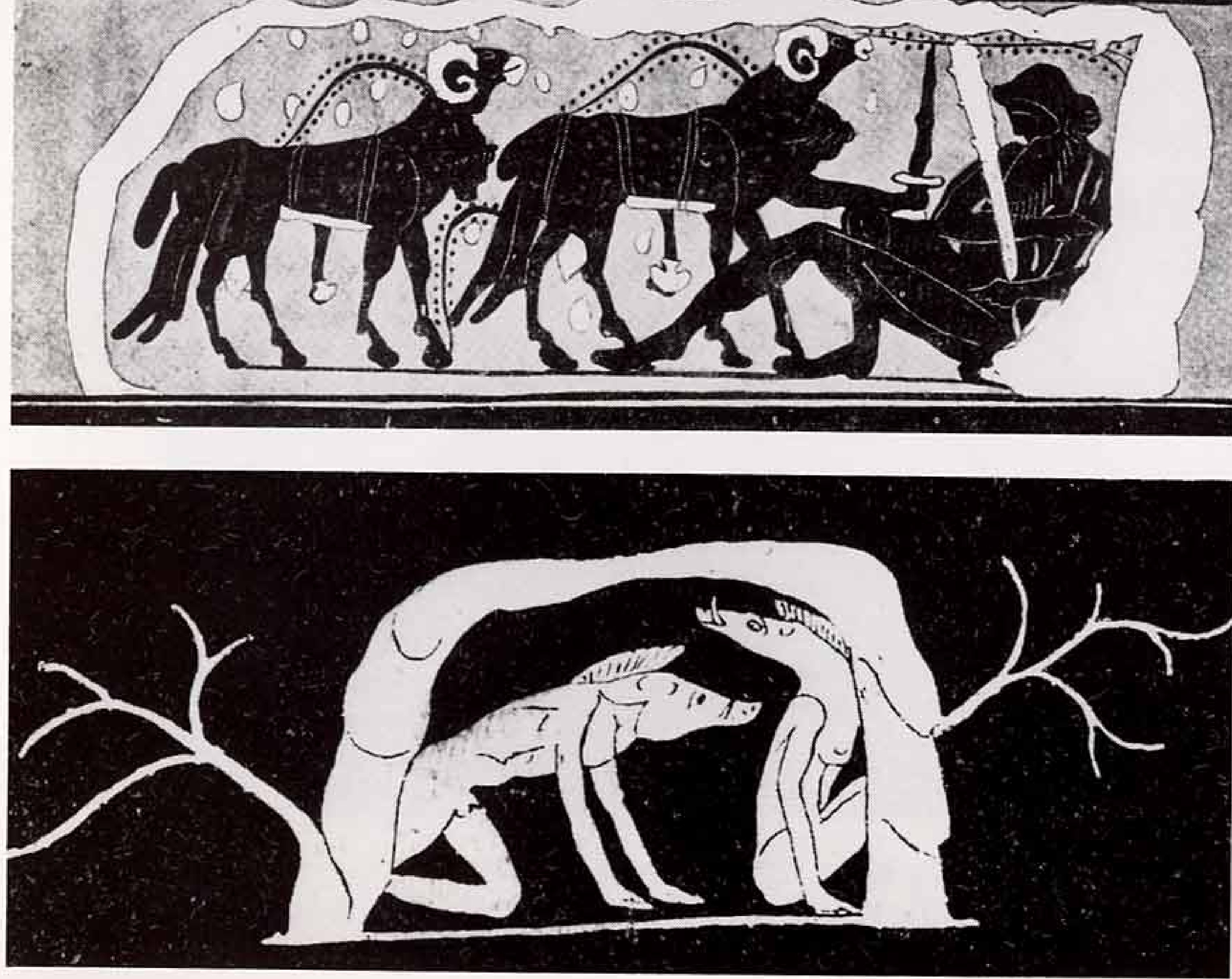

1. - Poséidon et Amymonè. Grotte en forme d'arc. Vers 430 (Silvia Hertig, Archäologische Sammlung der Universität Zürich).

2. - Grotte de Polyphème représentée de face. Vers $480(R A, 31$, 1897 , p. 30 , fig. 2.

3. - Grotte de Circé représentée de face. Vers 470 ( $R A, 31,1897$, p. 37, fig. 6 . 



1 et 2. - Grotte avec anodos de divinité. Cratère attique. Vers 390 (Cl. Bérard, Anodoi, pl. 10, fig. 35 a-b).

3. - Grotte d'Antiope. Peintre de Dircé. Vers 380 (Römische Mitteilungen, 84, 1977, pl. 111).

4. - Antre du lion de Némée. Vers 490 (photographie procurée par Herbert A. Cahn). Cliché D. Widmer (Bâle) n 7564. 

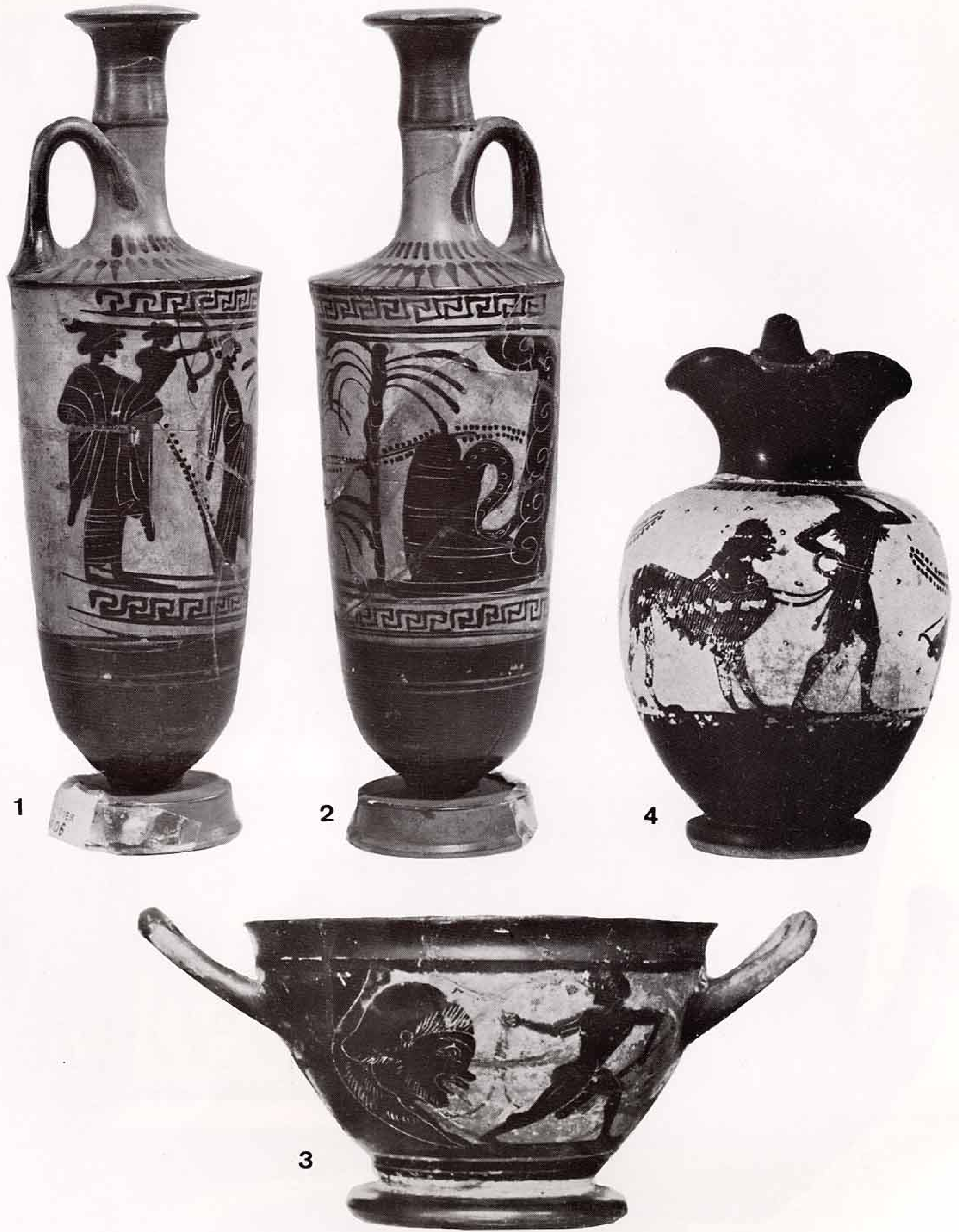

1 et 2. - Antre du dragon Python à Delphes. Vers 480. Photographies du Cabinet des Médailles, Bibliothèque Nationale, Paris.

3. - Lamia arrachée à son antre. Vers 480 (Festschrift Fr. Brommer, pl. 80, fig. 4).

4. - Lamia domptée par Héraclès. Vers 480 (Festschrift Fr. Brommer, pl. 80, fig. 2). 
Le langage des peintres de la figure rouge, un langage de dessinateurs, appelait toutefois des stylisations de la voûte au moyen d'un trait sans épaisseur. Il en est résulté des formes rigoureusement géométriques, fort différentes des bandeaux plus ou moins larges, peints en rehaut, dont l'ondulation marque l'irrégularité des ouvertures : sur un vase de Zurich (Pl. II, 1), Poséidon et Amymonè sont isolés du monde extérieur par un simple arc de cercle $\left({ }^{27}\right)$; sur le cratère de La Valette, c'est une ogive qui surplombe le jeune dieu surgissant des profondeurs $\left({ }^{28}\right)$.

La représentation d'une grotte posait aux peintres de vases grecs, à toutes les époques, des problèmes qu'ils ne pouvaient guère résoudre: sans les ressources de la perspective et sans les pouvoirs de la couleur, comment montrer l'espace d'une caverne, avec son obscurité ou son clair-obscur ? Comment en montrer simultanément l'extérieur et l'intérieur, ainsi que l'exigeait en général le récit de l'histoire ? Faute de savoir visualiser la grotte, la peinture de vases en a conçu des schémas codés, intelligibles dans un système de figuration, mais faiblement suggestifs si le spectateur n'abordait pas ces images avec son imaginaire, avec les «rêveries» - pour reprendre le mot de Bachelard - dont le folklore et la poésie avaient entouré l'antre sauvage.

De l'ensemble de la documentation paraît se dégager une règle générale : les peintres de la figure noire ont représenté la grotte de profil ; ceux de la figure rouge l'ont montrée de face (Fig. 1 et 2). On a soutenu que la modification était intervenue vers la fin du ve siècle, sous l'influence de la scénographie, peut-être sous celle d'Agatharque de Samos, à l'occasion de mises en scène paysagistes de l'Andromède d'Euripide en 412 ou du Philoctète de Sophocle en 409. Ce point de vue, défendu par W. Jobst dans son essai sur la grotte dans le théâtre grec $\left({ }^{29}\right)$, fut adopté par des spécialistes de l'iconographie comme T. Dohrn $\left({ }^{30}\right)$. Il me paraît pourtant irrecevable, certains documents conduisant à reconstruire une autre chronologie et une autre évolution de l'imagerie. C'est un fait qu'à l'époque archaïque la grotte est figurée par une épaisse bande de peinture noire, plus enflée ou plus resserrée, assez souvent garnie d'incisions et bordée de rehaut blanc pour indiquer l'anfractuosité de la paroi rocheuse. Ce montant, dans la plupart des cas, se recourbe un peu à son extrémité supérieure, mais il arrive qu'il fasse retour de manière à dessiner le plafond de la grotte dont on mesure ainsi la profondeur ( $\left.{ }^{31}\right)$. C'est toujours d'un seul côté de l'image qu'il s'élève. Lorsqu'il encadre la scène, c'est d'un défilé qu'il s'agit, d'une gorge montagneuse : avec les mêmes signes iconographiques, l'artiste évoque par ce dédoublement un autre paysage ( $\left.{ }^{32}\right)$. On en rencontre des exemples aussi bien $\mathrm{au} \mathrm{VI}^{\mathrm{e}}$ siècle qu'à l'époque du style sévère : cavalière au taureau passant entre deux falaises, ménade dansant parmi les rochers ${ }^{(33)}$. C'est pourquoi la nouvelle restitution graphique de

Suppl. IX, 1984, pp. 403-419, fig. 2-12, dresse un inventaire des grottes des Nymphes (habituellement associées à Pan), avec un commentaire et une bibliographie site par site, illustrés d'excellentes photographies de grottes sacrées. Sur les grottes de Pan, cf. aussi Ph. Borgeaud, Recherches sur le dieu Pan, 1979, pp. 73-114.

(27) Pélikè apulienne, Institut Archéologique de Zurich 2656 : E. Simon, LIMC, I, 1981, s.v. "Amymonè», n. 68.

(28) L'approche purement technique qui est la nôtre ici ne préjuge pas de l'interprétation iconographique dont la forme ogivale a été l'objet: Cl. Bérard, Anodoi. pp. 135-138, pl. , fig 55.

(29) Die Höhle im griechischen Theater des 5. und 4. Jahrhunderts v. Chr., Österreichische Akademie der Wissenschaften, Sitzungsberichts, 268, 1970, p. 123 sq. - On se reportera également à A. BERnAND, La carte du tragique. La géographie dans la tragédie grecque, 1985.

(30) «Helden und die Höhle», RM (voir n. 22), 84, 1977, pp. 211-217 et pl. 111 sq.

(31) Tel est notamment le cas pour la grotte du centaure Pholos sur le skyphos corinthien du Louvre (supra, n. 10) : voir ici-même, p. 156, Fig. 1,2.

(32) Fr. Villard avait mis en garde contre toute confusion et H. Lavagne, Operosa antra, p. 51, à juste titre, a repris ses observations.

(33) Cratère du Louvre à figures noires CA 2209: Para, 156,3; CVA, France 19, Louvre 12, pl. 189. Scyphos du Peintre de Brygos à New York, Metropolitan Museum 29.131.4 : CVA New York, pl.42 ; Grèce archä̈que, fig. 396. 


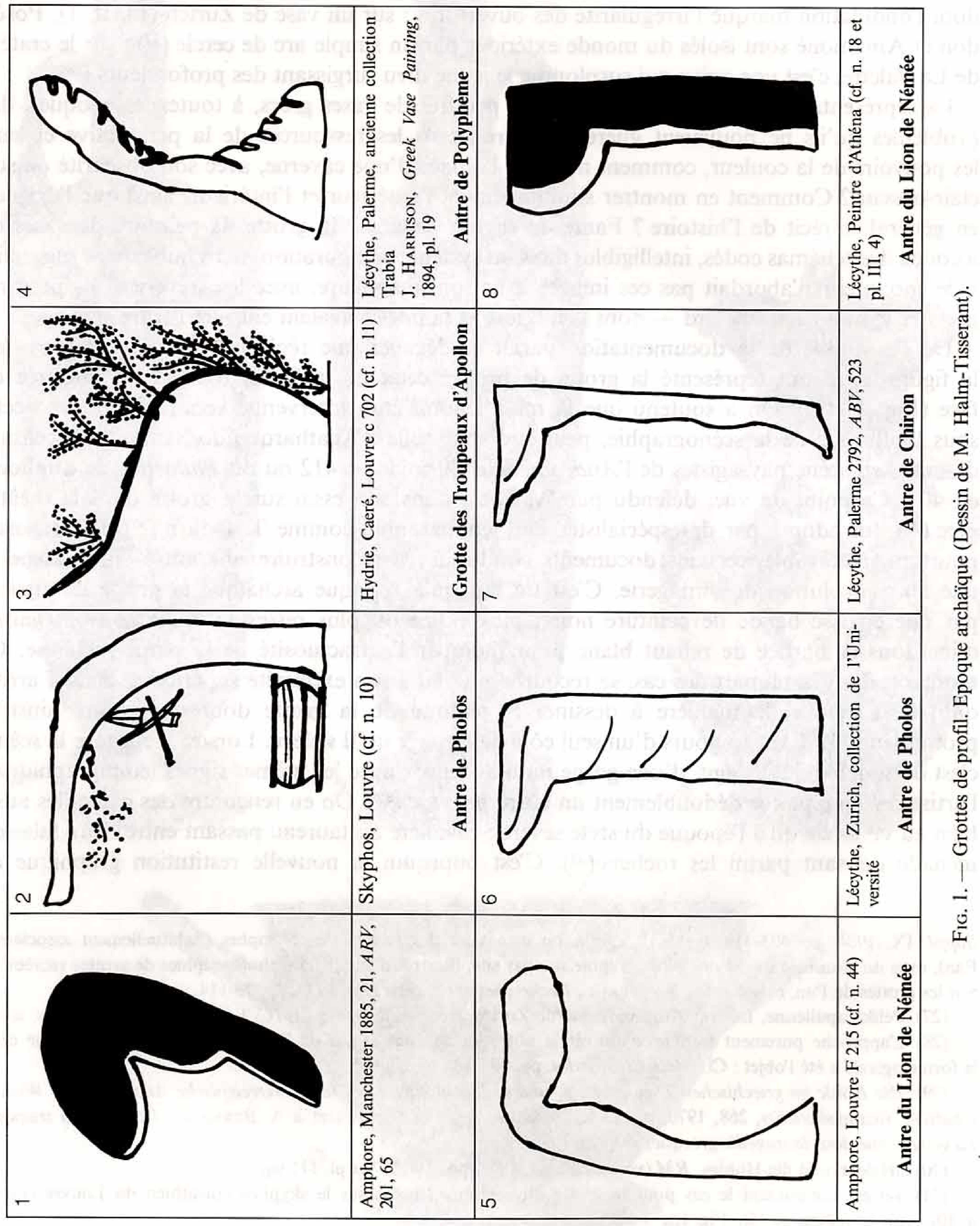


l'antre de Dionysos sur le coffre de Kypsélos, proposée par N. Papachatzi dans son édition de Pausanias, plus conforme aux usages des peintres archaïques, me paraît être préférable au dessin de W. von Massow où l'on voit le dieu se reposant entre deux parois rocheuses $\left({ }^{34}\right)$.

Un peintre a-t-il eu l'idée de faire la jonction entre les deux bandeaux latéraux, entre les deux parois, les reliant par une voûte et inventant ainsi la vue faciale de la grotte ? L'hypothèse rencontre des objections : outre l'imbrication entre deux formes de paysage qui avaient chacune son propre mode de figuration dans le répertoire des ateliers, il faut alors admettre, $\mathrm{au} \mathrm{v}^{\mathrm{e}}$ siècle, la concomitance du type à bandeaux, de tendance picturale, et du type à trait de contour que j'ai évoqué plus haut. T. Dohrn avait, à l'inverse, conclu au passage de la stylisation graphique par les dessinateurs d'Athènes à une picturalisation des façades de grottes, avec des effets de matière rocheuse et végétale, dans la peinture proto-italiote. Le Peintre de Dircé (Pl. III, 3), un des prédécesseurs de l'atelier de Paestum, semble occuper une position charnière dans cette évolution, a priori vraisemblable $\left({ }^{35}\right)$. Plusieurs documents bien datés entament pourtant la cohérence du raisonnement. Sur un lécythe à figures noires de l'ancienne Collection Rhousopoulos (Pl. II, 2), l'évasion des prisonniers de Polyphème se déroule comme sur une scène de théâtre, à travers l'ouverture d'une grotte vue de face : le cyclope est adossé contre la paroi droite; les fugitifs, sous leurs béliers, défilent à sa rencontre sous une voûte en rehaut blanc qui se referme derrière eux ${ }^{36}$ ). Un autre lécythe, à figures rouges (Pl. II, 3), que Beazley attribue à l'atelier du Peintre de Bowdoin ( $\left.{ }^{37}\right)$, représente les compagnons d'Ulysse métamorphosés en porcs, là encore sous la voûte d'une grotte vue de face, composée de blocs rocheux et plantée d'arbustes. Leurs jambes sont partiellement masquées, suggérant ainsi l'élargissement et les parties cachées de l'antre $\left({ }^{38}\right)$. Dès les années $480 / 470$, près d'un siècle avant le Peintre de Dircé, la peinture de vases attique connaissait donc le schéma de la grotte faciale à bandeau de contour dessinant l'ouverture. Du reste, la combinaison de la paroi unique avec les frondaisons d'arbres plantés à l'entour a sans nul doute facilité, plus anciennement qu'on ne croyait, la transition de la vue de profil à la vue de face. Sur une amphore à figures noires du Musée de Laon (Pl. I, 3), un grand cep de vigne se recourbe au-dessus de la tête de Dionysos pour faire jonction avec le rocher $\left.{ }^{(39}\right)$. Stylistiquement cette image ne relève pas du grand art et ce n'est pas un hasard si l'innovation est due précisément à des peintres populaires, très libres par rapport aux modèles des maîtres de la figure noire et de la figure rouge. On ne saurait sous-estimer l'intérêt de leur production, caractérisée par l'originalité d'un répertoire plus nourri de folklore que de mythologie littéraire, quelquefois par une étrange modernité de l'écriture et une veine paysagiste avant l'heure $\left({ }^{40}\right)$. C'est dans ces ateliers, dont la floraison coïncide avec celle de la peinture archaïque finissante, que l'on rencontre d'abord la représentation faciale et picturale de la grotte. Incompatible avec le style de la figure rouge classique, la formule, après une éclipse, triomphera au Iv $v^{\mathrm{e}}$ siècle.

(34) Papachatzi, op. cit. (supra, n. 13), p. 297 ; von Massow, Athenische Mitteilungen (= AM), 41, 1916, pl. 10.

(35) Supra, n. 30.

(36) Lécythe du Peintre d'Athéna, Musée National d'Athènes $1085: A B V, 528,40 ; A B L, \mathrm{n}^{\circ} 122$; P. Perdrizet, «Polyphème», $R A, 31,1897$, p. 30. - Par un illogisme significatif dans la construction de l'espace (voir supra, n. 22), les arbres sont recoupés par les béliers et semblent ainsi pousser au fond de la grotte !

(37) Musée National d'Athènes $9685: A R V^{2}, 693,3 ; R A, 31,1897$, pp. 28 et 37.

(38) Le peintre n'a pas en mémoire les étables de la Circé homérique ; il représente une simple mandra, comme d'après nature.

(39) Para, 297 ; CVA France 20, Laon 1, pl. 7, 3. Peintre d'Oxford 216.

(40) M. Halm-Tisserant, L'enfant dans le chaudron, Paris, 1992, p. 17. 


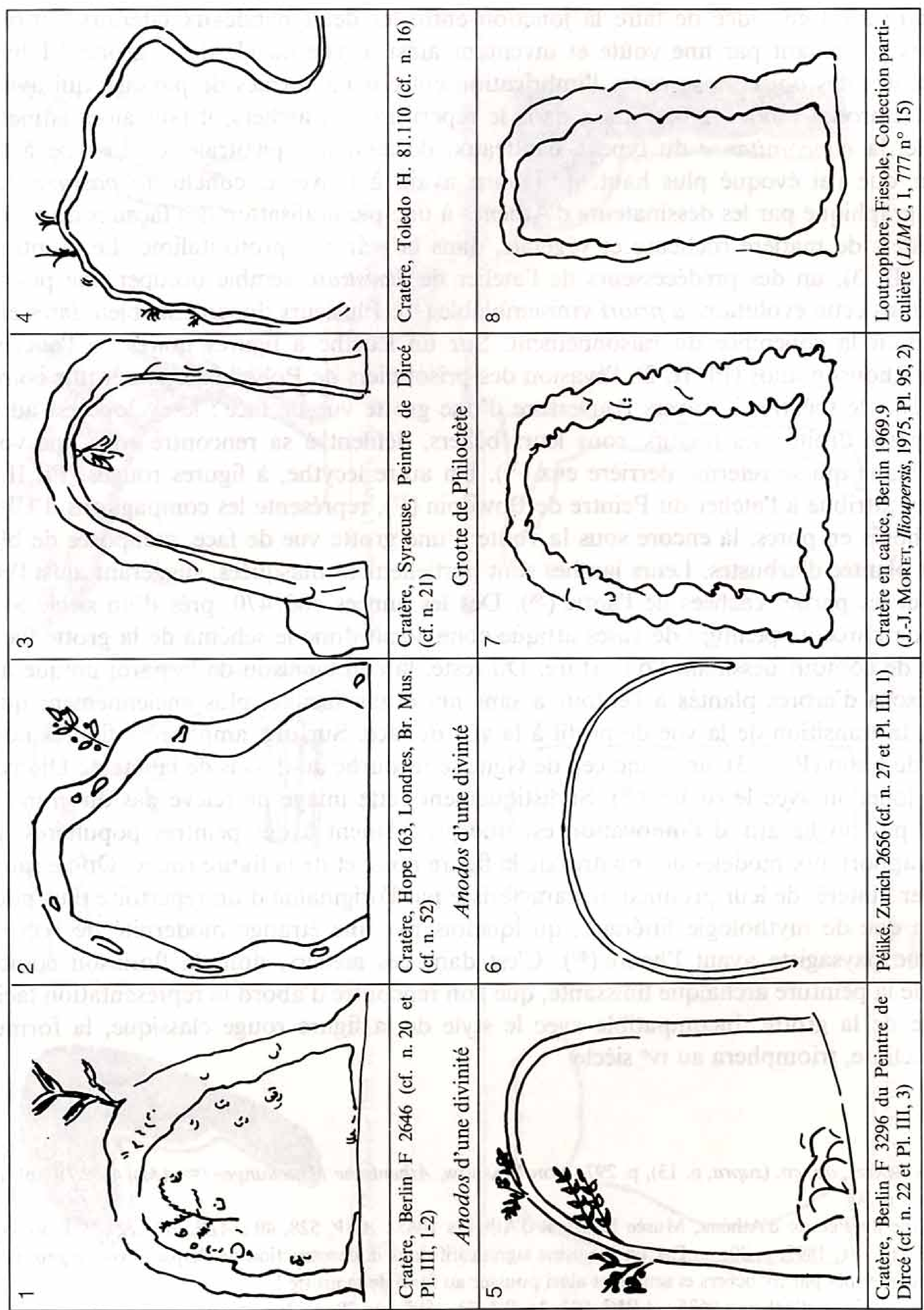

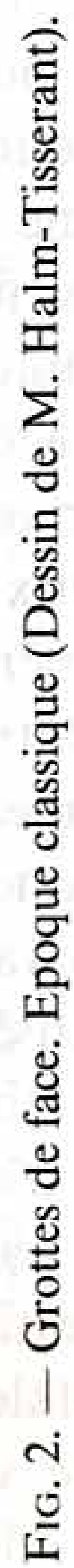


L'aporie figurative que devaient affronter les peintres de vases (rendre la profondeur, montrer simultanément l'habitacle caverneux et sa façade) les conduisait à user d'expédients. Le peintre de l'hydrie de Caeré au Musée du Louvre ${ }^{\left({ }^{41}\right)}$ procède de façon naïvement paratactique : d'un côté, la chambre de Maia, avec les palabres autour du berceau d'Hermès; de l'autre, l'entrée et les abords de la deuxième grotte de l'hymne homérique ${ }^{(22}$, dissimulée dans une forêt giboyeuse. L'espace est construit de telle sorte que, dans la vision de profil, le troupeau d'Apollon occupe à la fois le fond et l'accès de la caverne. Le système de représentation est le même sur un lécythe du Peintre d'Athéna $\left({ }^{43}\right)$. Plutôt que la lutte héroïque, dans la tradition d'Euphronios, l'artiste préfère évoquer les lieux où Héraclès va combattre le lion de Némée (Pl. III, 4). L'avant-train du fauve surgit de l'ouverture rocheuse, se détachant sur fond de végétation, avec le cerf qu'il vient de terrasser. L'image donne moins à voir qu'à imaginer, puisqu'elle montre et dissimule tout ensemble le théâtre et le personnage principal de l'action ( $\left.{ }^{44}\right)$. La mise en forme paysagiste est parfois plus complexe. Pour représenter le combat d'Apollon contre le dragon chthonien de Delphes, le Peintre d'Hémon ${ }^{\left({ }^{45}\right)}$ s'inspire d'un récit dont Euripide se souvient à son tour, quelques décennies plus tard (Iphigénie en Tauride, vv. 1234-1283). Le choix de la vue de profil est conforme au schéma dominant de l'époque, mais en avant de la caverne se détache un énorme bloc, une sorte de bouclier en pierre qui protège Python contre les flèches de l'enfant divin (Pl. IV, 1 et 2). Sur le terrain on attribue par convention à Létô l'un des rochers de la place de l'aire $\left.{ }^{46}\right)$, mais on ne sait rien de l'antre du dragon qui, à tout le moins, avait existé dans l'imagination populaire: le décorateur du lécythe et le poète tragique en témoignent l'un et l'autre. A propos de la fête delphique du Septerion, qui commémorait le combat, Plutarque s'étonnait que l'on représentât un antre sous la forme d'une cabane ou d'une coulisse de théâtre $\left({ }^{47}\right)$.

Les dessins de la Fig. $3\left({ }^{48}\right)$ transcrivent en vues de face des compositions d'époque ou de tradition archaïques qui associent une scène d'action à une grotte rendue de profil. Pour ludique qu'elle puisse paraître, la tentative ne laisse pas d'être instructive. Elle souligne les insolubles difficultés techniques contournées par les schématisations et les conventions qu'on a analysées. Elle met en évidence les transpositions mentales, l'aptitude à voir et à imaginer qu'il faut prêter au spectateur grec devant l'antre du lion de Némée ou du dragon de Delphes. Le face à face entre les héros et les monstres à l'entrée de leurs repaires acquiert, quand on le visualise graphiquement, une précision et une logique superficielles de bande dessinée. Il y a plus de force suggestive dans les représentations tronquées des grottes grecques. Déjà celles des urnes hellénistiques de Volterra, sculptées dans l'albâtre et situant Philoctète, Polyphème, Andromède dans un espace «réel», prennent un air paradoxalement plat de maquettes ou de crèches (49)

(41) Supra, n. 11.

(42) Hymne à Hermès, vv. 397-404.

(43) Supra, n. 18 (marché de Bâle).

(44) Une amphore du Peintre de Rycroft juxtapose au contraire et même accumule les points de vue et les détails : grotte à plafond servant de perchoir à un oiseau; scène du combat au dehors, avec palmier à l'arrière-plan; la massue d'Héraclès se trouve appuyée contre le fond de la grotte. Amphore du Louvre F 215: $A B V, 336,10 ; C V A$, France 4, Louvre 3, pl. $27,7$.

(45) E. PfuHL, $M Z$, p. 75 , fig. 284 ; L. KAHIL, loc. cit. (supra, n. 18).

(46) J.-Fr. Bommelaer, Guide de Delphes. Le site, École française d'Athènes, 1991, p. 144, nº 327.

(47) Ibid., p. 146 sq.

(48) L'illustration graphique (Fig. 1-3) a été réalisée par M. Halm-Tisserant.

(49) Dohrn, op. cit. (supra, n. 30), pp. 218-227, pl. 112-115. La même observation vaut pour les pinakes de Locres (bibliographie dans Operosa antra, pp. 149-154) ou les bols à reliefs : grotte des amours de Zeus et d'Antiope sur le bol 11798 du Musée National d'Athènes (U. SinN, Homerische Reliefbecher, AM, Beiheft, 7, 1979, p. 109 et pl. 21, 
Le lion de Némée :
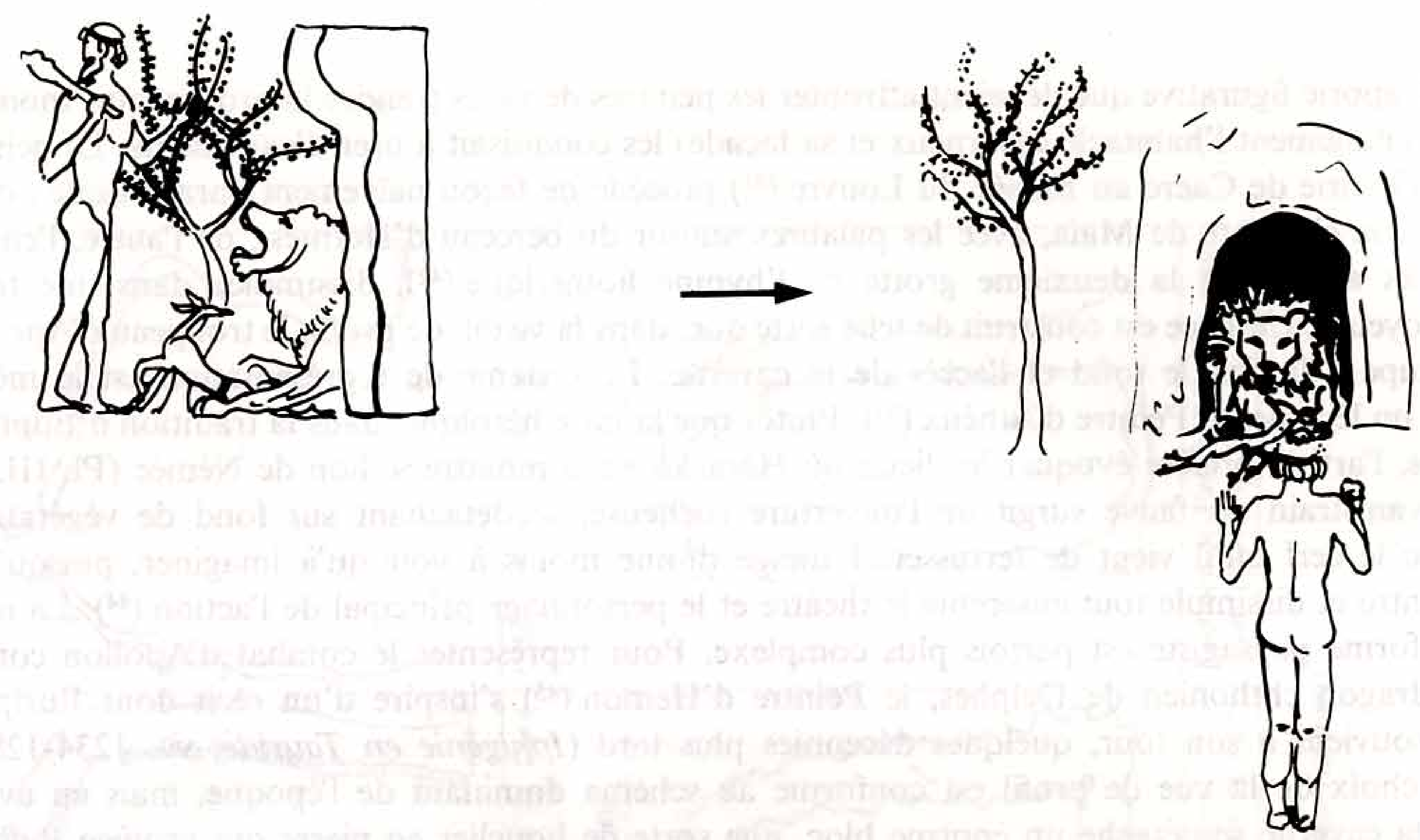

Le serpent et Apollon :
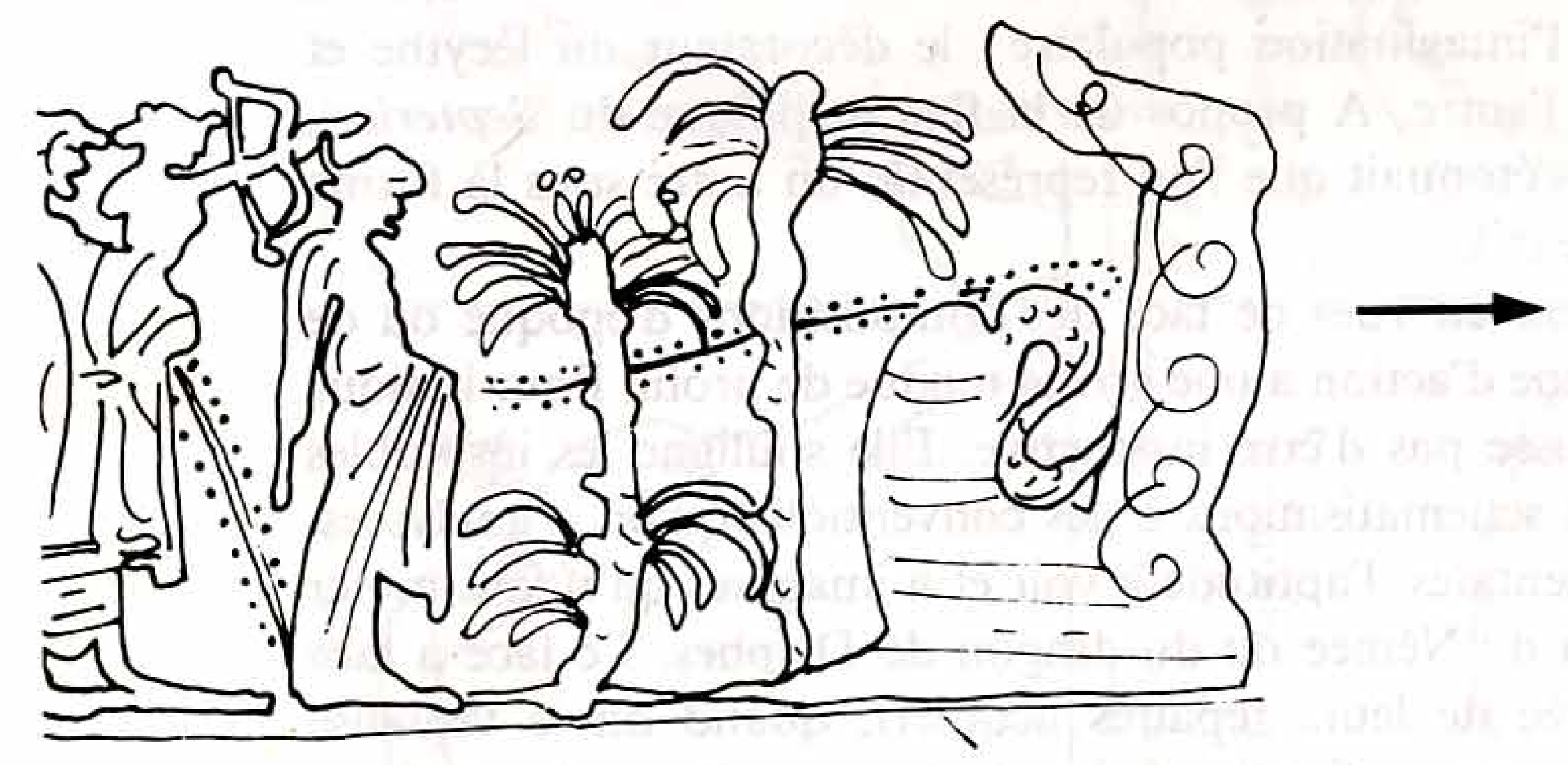

Les troupeaux d'Apollon :
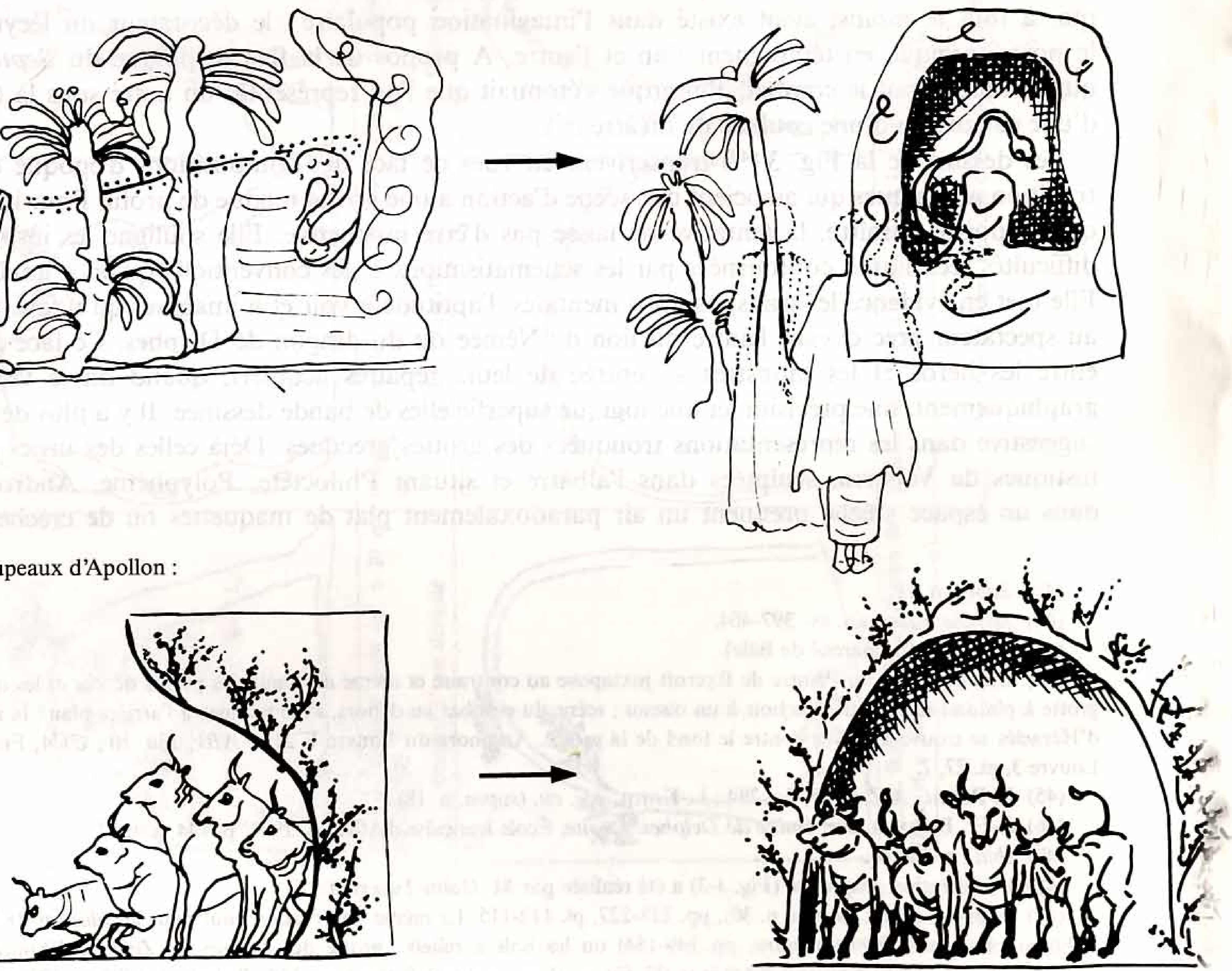

FIG. 3. - Grottes de profil converties en vues de face, avec les personnages de l'action : antres du lion de Némée et du dragon Python, grotte des troupeaux d'Apollon (Dessin de M. Halm-Tisserant). Cf. nn. 18 et 11, pl. III, 4 et IV, 1-2. 
Il faut revenir une dernière fois au Peintre d'Athéna, à ses compositions qui représentent vraisemblablement la capture de la croquemitaine Lamia (Pl. IV, 3 et 4). Sur une oenochoé de Boston $\left({ }^{50}\right)$, Héraclès, l'ayant domptée, la conduit par une laisse ; sur un scyphos de Copenhague $\left({ }^{51}\right)$, il l'arrache d'une caverne d'où dépasse seulement sa tête colossale. Entre les deux scènes le lien était établi par le souvenir des histoires que les conteurs et les nourrices racontaient aux enfants grecs.

Plus peut-être que d'autres images de la peinture de vases, les images de grottes ont besoin, pour produire tout leur effet, de l'imagination du spectateur. Cela tient autant au sujet luimême («paura e desidero») qu'aux difficultés techniques de la représentation. Sur le cratère Hope (52), le mouvement de l'anodos est purement vertical. Pour rendre sensible au regard le paysage de cette épiphanie, le peintre ne disposait d'aucun des moyens d'un Monsu Desiderio creusant les abîmes de ses Enfers, en se souvenant des catacombes napolitaines de San Gennaro et des grottes du Pausilippe ${ }^{53}$ ).

\section{Gérard Siebert (Strasbourg)}

MB 51). Seul un traitement résolument décoratif de la grotte, avec le motif des lotus-nelumbo sur les bols ioniens (A. Laumonier, Exploration archéologique de Délos, XXXI, 1977, La céramique hellénistique à reliefs, 1. Ateliers «ioniens», pl. 116 sq., parle alors de «lotus-paradis»), produit des effets satisfaisants. Sur les reliefs attiques en marbre consacrés aux Nymphes, l'espace de la grotte est traité avec discrétion, du moins au ive siècle, le bandeau de contour de l'ouverture rappelant celui des grottes peintes (état de la question dans Operosa antra, pp. 73-80).

(50) ABV, 524, 1: J. Boardman, Athenian Black-Figure Vases, Londres, 1978, p. 160, fig. 253; Iconographie de Lamia : M. Halm-Tisserant, «Folklore et superstition en Grèce classique», Kernos, 2, 1989, pp. 67-82.

(51) E. T. Vermeule, Festschrift Fr. Brommer (U. Hückmann, A. Krug éd.), 1977, p. 297, pl. 80.

(52) Musée Britannique, 1917.2-21.1: Metzger, Représentations, p. 262, pl. XXXV; Bérard, Anodoi, p. 104, pl. 10, fig. 34 .

(53) P. Seghers, Monsu Desiderio ou le théâtre de la fin du monde, Paris, Robert Lafon, 1981, pp. 88-114. François de Nomé et Didier Barra (dont on admet qu'ils forment ensemble Monsu Desiderio), peintres lorrains, Napolitains d'adoption, se sont vraisemblablement inspirés de ces souterrains pour la représentation de leurs Enfers. 